\title{
The two sides of cytokine signaling and glaucomatous optic neuropathy
}

\author{
Ping Huang $•$ Samuel Shao-Min Zhang $\cdot$ Chun Zhang
}

Published online: 9 September 2009

(C) The Author(s) 2009. This article is published with open access at Springerlink.com

\section{Erratum to: j ocul biol dis inform DOI 10.1007/s12177-009-9026-6}

The following article was mistakenly run in volume 2 , issue 2 (June 2009) instead of in the present special issue, for which it was intended. Please also see additional corrections to the dates originally listed in Table 3. The publisher regrets the error.

\begin{abstract}
The mechanistic study of glaucoma pathogenesis has shifted to seeking to understand the effects of immune responses on retinal ganglion cell damage and protection. Cytokines are the hormonal factors that mediate most of the biological effects in both the immune and nonimmune systems. CD4-expressing $\mathrm{T}$ helper cells are a major source of cytokine production and regulation. Type 1 helper $\mathrm{T}$ (Th1) cells are characterized by the production of proinflammatory cytokines such as interferon-gamma, interleukin (IL)-2, IL-12, IL-23, and tumor necrosis factor-alpha while type 2 helper T (Th2) cells are characterized by the production of IL-4, IL-5, IL-6, and IL10. The balance of Th1/Th2 cytokine production influences many pathological processes and plays both causative and protective roles in neuronal damage. Growing evidence indicates that imbalances of $\mathrm{Th} 1 / \mathrm{Th} 2$ cytokine production are involved in neural damage or protection in many neurological diseases. In this review, we discuss the possible roles of Th1/ Th2 cytokine production and imbalance of Th1/Th2 cytokines in retina, especially glaucomatous optic neuropathy.
\end{abstract}

The online version of the original article can be found at http://dx.doi. org/10.1007/s12177-009-9026-6.

P. Huang $\cdot$ C. Zhang $(\bowtie)$

Peking University Eye Center, Peking University Third Hospital,

Beijing 100083, China

S. S.-M. Zhang $(\bowtie)$

Department of Neural and Behavioral Sciences, Penn State

University College of Medicine,

Hershey, PA 17033, USA

e-mail: ssz3@psu.edu
Keywords Glaucoma Cytokines · Neuropathy · Neuroprotection

\section{Introduction}

Glaucoma is one of the leading causes of vision loss as a result of impairment of retina ganglion cells (RGCs). Although lowering of intraocular pressure (IOP) is currently the method of choice for the treatment of glaucoma, glaucomatous neuropathy may still develop and lead to loss of vision [1]. There are no other effective therapeutic and/or preventive interventions. Other mechanisms, besides the increase in IOP, have been associated with degeneration of RGCs. These include ischemia, glutamate excitotoxic stress, high reactive oxygen species production, and the loss of mitochondrial function. Recent mechanistic studies have focused on immunological changes during glaucomatous pathogenesis and possible preventive therapies [2]. The major targets of interest are cytokines and their functions in damage or protection of retinal ganglion cells. Recent advances in the studies of glaucoma or RGCs reveal that cytokines are a possible factor in the pathogenesis of glaucoma and may regulate RGCs survival or death. Here, we will review the roles of both type 1 helper $T$ (Th1)derived and type 2 helper $\mathrm{T}$ (Th2)-derived cytokines in the damage or protection of RGCs and the possible relationship of these cytokines with human glaucoma.

\section{Cytokines from $\mathbf{T}$ helper cells and neuronal diseases}

CD4-expressing $\mathrm{T}$ helper cells develop into two major subtypes of cells known as Th1 and Th2 cells [3, 4]. The two subtypes produce different sets of cytokines, which are involved in many physiological and pathological processes in humans. It has been considered that Th1 cells are 
characterized by the production of proinflammatory cytokines such as IFN- $\gamma$, IL-2, IL-12, IL-23, and TNF-alpha while Th 2 cells are characterized by the production of IL-4, IL-5, IL-6, and IL-10 (Fig. 1). We now know that this classification is an oversimplification, and that the effects of cytokines are far more complicated in the tissue and cells in response to stress.

The functions of $\mathrm{T}$ helper cytokines have been extensively studied in a number of different conditions $[5,6]$, including neural damage and protection. In the autoimmune central nervous system disease multiple sclerosis and its animal model experimental autoimmune encephalomyelitis (EAE), T helper lymphocytes play a crucial role in inflammatory tissue damage to the neurons [7]. Cytokines, such as interferon-gamma, are also involved in neuron damage resulting from nonautoimmune conditions such as ischemia [8] and a number of neurodegenerative diseases [9]. In contrast, $T$ helper cytokines can also play significant roles in protection against neural cell death [10], indicating two aspects of cytokine function, namely, in neural damage and protection.

\section{Cytokines play essential roles in retina neural damage}

The causes of RGC death have been studied in many model systems in vitro and in vivo, including glutamate or $N$ methyl-D-aspartate (NMDA) ocular injection and cytotoxicity, increase of intraocular pressure (IOP), ischemia/ reperfusion (I/R), axotomy of optic nerves, optic nerve crush, experimental autoimmune uveoretinitis (EAU), EAE, and serum deprivation in cultured neural cells. Evidence over the past decade has revealed that cytokines produced from both Th1 and Th2 cells were involved in RGCs death

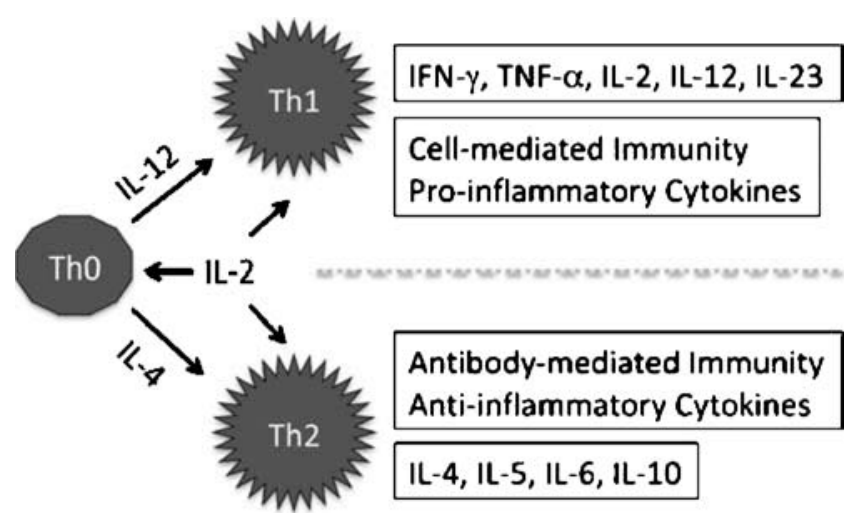

Fig. 1 Th1 and Th2 cytokine signaling and T helper cells. Th1 and Th2 cells can be induced from Th0 cells by IL-12 and IL-4, respectively. IL-2 promotes Th0 cell and also Th1 and Th2 cell proliferation. The major cytokines produced by Th1 or Th2 cells are listed in response to the insults listed above. Detailed information is listed in Table 1.

Increased levels of Th1 cytokines, such as IFN-gamma [11], IL-1 [12], IL-2 [13], IL-17 [13], and TNF-alpha [11, 13-18] were reported to be significantly associated with retina and RGC damage caused by distinct insults in vivo and in vitro, while IL- 6 is the only Th2 cytokine that has been reported to show similar results $[11,19]$. Most work has been focused on the actions of TNF-alpha. TNF-alpha was first found elevated in retina following increase of hydrostatic pressure. RGC apoptosis rates were attenuated approximately $66 \%$ by neutralizing antibody against TNFalpha [14]. An increase of TNF-alpha expression has been associated with the most severely damaged optic nerve heads from human glaucomas [15], indicating that TNFalpha contributes to the progression of optic nerve degeneration in this disease. Later work has confirmed that TNF-alpha is a critical cytokine in RGC damage caused by different insults, such as EAU [13], optic nerve crush [20], and serum withdrawal [11] in vitro. Direct ocular injection of TNF-alpha [16] in vivo also results in RGC death.

The Th2 cytokine IL- 6 is a member of a large cytokine family that triggers the gp 130 receptor and activates signal transducer and activator of transcription 1 (STAT1) and STAT3 in response to stress [21]. IL-6 has been considered a neurotrophic factor in protection of neurons from damage in many neural degenerative conditions [22, 23]. While IL6 can play a neuroprotective role in retina, as described below, it has been shown to be involved in retina or RGC damage under a number of different conditions [11, 19]. In a study of Rho-kinase inhibition on retinal cell survival, the reduction of proinflammatory cytokines including TNFalpha, IFN-gamma, and IL-6 likely contributed to the significantly lower toxicity on retina explants [11]. Other evidence showed that IL- 6 deficiency could increase the rate of RGC survival during the first $24 \mathrm{~h}$ after optic nerve injury [19], indicating the complexity of IL-6 in both retina damage and protection.

IL-17 is produced by Th17 cells. This cell type can be stimulated to expand by IL-2 and IL-23. Besides IL-17 production, Th17 cells also secrete IL-6 and TNF-alpha and now are recognized as causative agents of several diseases previously attributed to Th1 cells, such as chronic inflammatory bowel disease [24]. IL-17 is an agent that contributes to retina damage in an EAU model [13]. Retinal damage in this model can be reduced by a neutralized by specific anti-IL-17 antibody.

\section{Cytokines in retina neural protection}

A significant number of studies on cytokine protection of neurons have been performed and these numbers are 
Table 1 Cytokines in retina neural damages

\begin{tabular}{|c|c|c|c|c|c|c|c|}
\hline Cytokines & Systems & Methods & Cell types & Insults & Results & Author & Year \\
\hline IFN-g & Animals & In vitro & Retina explants & Serum deprivation & RGC damage & Tura & 2009 \\
\hline \multirow[t]{4}{*}{ IL-1b } & Animals & In vitro & RGC & Survival & RGC damage & Abcouwer & 2008 \\
\hline & Animals & In vivo & RGC & NMDA & RGC damage & Kitaoka & 2007 \\
\hline & Animals & In vivo & RGC & $\mathrm{I} / \mathrm{R}$ & RGC damage & Zhang & 2004 \\
\hline & Animals & In vivo & RGC & $\mathrm{I} / \mathrm{R}$ & RGC damage & Yoneda & 2001 \\
\hline IL-2 & Animals & In vivo & Retina & EAU & Retina damage & Amadi-Obi & 2007 \\
\hline \multirow[t]{2}{*}{ IL-6 } & Animals & In vitro & Retina explants & Serum deprivation & RGC damage & Tura & 2009 \\
\hline & Animals & In vivo & $\mathrm{RGC}$ & Glutamate toxicity & RGC damage & Fisher & 2001 \\
\hline IL-17 & Animals & In vivo & Retina & EAU & Retina damage & Amadi-Obi & 2007 \\
\hline \multirow[t]{7}{*}{ TNF-a } & Animals & In vivo & Retina & EAU & Retina damage & Amadi-Obi & 2007 \\
\hline & Animals & In vitro & Retina & Serum deprivation & RGC damage & Tura & 2009 \\
\hline & Animals & In vitro & Retina explants & Culture & RGC damage & Hong & 2009 \\
\hline & Animals & In vivo & $\mathrm{RGC}$ & IOP & RGC damage & Nakazawa & 2006 \\
\hline & Animals & In vivo & RGC & TNF-a injection & RGC damage & Kitaoka & 2006 \\
\hline & Animals & In vitro & RGC & Survival & RGC damage & Tezel & 2000 \\
\hline & Human & In vivo & Optic nerve & Expression & Optic nerve damage & Yuan & 2000 \\
\hline TNFR-1 & Animals & In vivo & RGC & Optic nerve crush & RGC damage & Tezel & 2004 \\
\hline
\end{tabular}

increasing year after year. As with the studies on neural damage, many kinds of insults have been used to test the roles of cytokines in protection of retinal neurons both in vivo and in vitro. In an EAU model, IL-27 and IFN-gamma have been shown to inhibit IL-2-induced expansion of IL-17, produced by Th17 cells, and to ameliorate retina damage by EAU [13]. This indicates that Th1 cytokines such as IFN-gamma could have protective roles on neurons under certain circumstances. In a similar case, IL-1, a mediator of neural injury, has a protective role by preventing neuronal cell death from glutamate neurotoxicity [25]. TNF-alpha, a clear mediator for neural damage, also can prevent secondary death of RGCs after axotomy of the optic nerve in vivo [26].

Th2 cytokines such as IL-4, IL-6, and IL-10 show neuroprotective functions in many different types of RGC injury such as optic nerve axotomy [27] and ischemia/ reperfusion [28] in vivo and serum deprivation [29] in vitro (Table 2). Intraocular administration of adenoviral vectors encoding IL-10 and IL-4 may help prevent neurodegeneration caused by the activation of glial cells postaxotomy [27]. IL-6 is upregulated after retinal ischemia/reperfusion injury, and its expression by microglia/phagocytic cells may protect neurons in the RGC layer from this insult. Exogenously added IL-6 protects the inner retina after ischemia/reperfusion injury [28]. Our studies on STAT3 [30], the downstream effector of IL-6 and IL-10, have shown that STAT3 activation is essential for RGC survival, and persistent activation of STAT3 by neurotrophic factors and cytokines provides strong neuroprotection. This suggests that STAT3 activation will be an effective strategy in a number of chronic retinal diseases.
Cell-mediated immunity and inflammatory responses are also thought to be involved in neural damage and protection. There is evidence that inflammatory leukocyte recruitment can play a causative role in RGC cell death in NMDA-induced excitotoxicity. Anti-inflammatory agents improved RGC survival [31], suggesting that increases in inflammatory responses can lead to neural damage. On the other hand, an evoked T cell-dependent response has been shown to help neuron survival [32]. It was reported that using a single low dose of whole-body or lymphoid-organ gamma-irradiation significantly increased $\mathrm{T}$ cell-dependent responses, and this improved the spontaneous recovery of neurodegenerative conditions caused by injection of a toxic dose of intraocular glutamate [33]. Animals with severe immune deficiency or deprived of mature $\mathrm{T}$ cells were unable to benefit from this treatment [33], suggesting that this neuroprotection is immune mediated.

\section{Cytokines in glaucomatous optic neuropathy}

Alterations of cytokines in human glaucoma have been studied for over three decades. Fibroblasts from Tenon's capsule are cellular components that contribute to unsuccessful glaucoma filtration surgery. Using the materials from Tenon's capsule [34], many studies have been performed with examination of IFN signaling including IFN-alpha, IFN-beta, and IFN-gamma. As shown in Table 3, both IFN-alpha2b [35] and IFN-gamma [36] inhibit the fibroblast proliferation from Tenon's capsule in vitro. More recently, IL-1 has been linked to an increase in extracellular 
Table 2 Cytokines in retina neural protection

\begin{tabular}{|c|c|c|c|c|c|c|c|}
\hline Cytokines & Systems & Methods & Cell types & Insults & Results & Author & Year \\
\hline IFN-b1a & Animals & In vivo & Optic nerve & EAE & Optic nerve protection & Sättler & 2006 \\
\hline IFN-b1b & Animals & In vivo & RGC & EAE & RGC protection & Maier & 2006 \\
\hline IFN-g & Animals & In vivo/in vitro & Retina & EUA & Retina protection & Amadi-Obi & 2007 \\
\hline IL-1 & Animals & In vitro & Glail cell & Glutamate toxicity & RGC protection & Namekata & 2008 \\
\hline IL-1b & Animals & In vivo & RGC & Axotomy & RGC protection & Diem & 2003 \\
\hline IL-2 & Animals & In vitro & RGC & Survival & RGC protection & Sholl-Franco & 2001 \\
\hline \multirow[t]{2}{*}{ IL-4 } & Animals & In vivo & RGC & Axotomy & RGC protection & Koeberle & 2004 \\
\hline & Animals & In vitro & RGC & Survival & RGC protection & Sholl-Franco & 2001 \\
\hline \multirow[t]{2}{*}{ IL-6 } & Animals & In vivo & RGC & $\mathrm{I} / \mathrm{R}$ & RGC protection & Sanchez & 2003 \\
\hline & Animals & In vitro & RGC & Survival & RGC protection & Mendonça Torres & 2001 \\
\hline \multirow[t]{2}{*}{ IL-10 } & Animals & In vivo & RGC & Axotomy & RGC protection & Koeberle & 2004 \\
\hline & Animals & In vitro & RGC & Serum deprivation & RGC protection & Boyd & 2003 \\
\hline IL-27 & Animals & In vivo & Retina & EAU & Retina protection & Amadi-Obi & 2007 \\
\hline STAT3 & Animals & In vitro/in vivo & RGC & $\mathrm{I} / \mathrm{R}$ and Glutamate toxicity & RGC protection & Zhang & 2008 \\
\hline TNF-a & Animals & In vivo & RGC & Axotomy & RGC protection & Diem & 2001 \\
\hline Leukocyte recruitment & Animals & In vivo & RGC & NMDA & RGC protection & Nakazawa & 2007 \\
\hline T autoimmunity & Animals & In vivo & RGC & Optic nerve crush & RGC protection & Kipnis & 2004 \\
\hline T autoimmunity & Animals & In vivo & RGC & Optic nerve crush & RGC protection & Yoles & 2001 \\
\hline
\end{tabular}

matrix metalloproteinase-3 (MMP-3). IL-1alpha, and IL1 beta each individually can increase MMP-3 expression in the trabecular meshwork [37], and this affected the aqueous humor outflow facility. TNF-alpha, in combination with IL1alpha or IL-1beta, produced intense synergistic increases in MMP-3 and MMP-12 but not in MMP-9. These results suggested a relationship between cytokines and glaucoma pathogenesis.

Recent work has focused on the relationship between cytokine production and glaucomatous optic neuropathy.

Table 3 Cytokines in human glaucoma studies

\begin{tabular}{|c|c|c|c|c|c|c|}
\hline Cytokines & Systems & Methods & Cell types & Results & Author & Year \\
\hline IFN-a2b & Human & In vitro & Tenon's capsule fibroblasts & Inhibit cell proliferation & Gillies & 1993 \\
\hline IFN-g & Human & In vitro & Tenon's capsule fibroblasts & Inhibit collagen synthesis & Nguyen & 1994 \\
\hline IFN-g & Human & In vivo & Blood serum & No change in glaucoma & Huang & unpublished \\
\hline IL-1 & Animals and Human & In vitro & Trabecular meshwork & Increase MMP-3 MMP-12 & Kelly & 2007 \\
\hline IL-1 & Human & In vitro & Trabecular meshwork & ELAM-1 & Wang & 2001 \\
\hline IL-1 & Human & In vitro & Trabecular meshwork & p38 or JNK activation & Zhang & 2006 \\
\hline IL-2 & Human & In vivo & Blood serum & No change in glaucoma & Yang & 2001 \\
\hline IL-2 & Human & In vivo & Blood serum & No change in glaucoma & Huang & unpublished \\
\hline sIL-2R & Human & In vivo & Blood serum & High in glaucoma & Yang & 2001 \\
\hline sIL-2R & Human & In vivo & Blood serum & No change in glaucoma & Huang & unpublished \\
\hline IL-4 & Human & In vivo & Blood serum & High in glaucoma & Huang & unpublished \\
\hline IL-6 & Human & In vivo & Blood serum & Low in glaucoma & Huang & unpublished \\
\hline IL-10 & Human & In vivo & Blood serum & High in glaucoma & Yang & 2001 \\
\hline IL-12p40 & Human & In vivo & Blood serum & High in glaucoma & Huang & unpublished \\
\hline IL-12p70 & Human & In vivo & Blood serum & No change in glaucoma & Huang & unpublished \\
\hline IL-23 & Human & In vivo & Blood serum & Low in glaucoma & Huang & unpublished \\
\hline TNF-a & Animals and Human & In vivo & Trabecular meshwork & Increase MMP-3 MMP-12 & Kelley & 2007 \\
\hline TNF-a & Human & In vitro & Optic nerve & High in glaucoma & Yang & 2000 \\
\hline TNF-a & Human & In vitro & Blood serum & Low in glaucoma & Huang & unpublished \\
\hline
\end{tabular}


High levels of sIL-2R and IL-10 have been found in the serum of glaucoma patients compared with their normal controls $[38,39]$. An increase in $\mathrm{CD} 3(+) / \mathrm{CD} 8(+)$ lymphocytes was also associated with glaucoma, indicating that cellular immunity plays an important role in the initiation and/or progression of glaucomatous optic neuropathy. Recently, we compared human serum levels of Th1 and Th2 cytokines among two stages of primary open-angle glaucoma (POAG) and nonglaucomatous controls (Huang et al., unpublished data). The results showed that patients with POAG exhibited a significant elevation of IL-4 and a significant reduction of IL-6 compared to the control group, while no significant differences in IL-4 and IL-6 levels were observed between patients with severe optic neuropathy and patients with mild optic neuropathy. The level of IL-12p40 was significantly increased in patients with POAG compared to controls, while the average levels of IL-23 and TNF-alpha were significantly reduced in the POAG patients groups compared with controls. (Huang et al., unpublished data).

\section{In conclusion}

The interplay of Th1 and Th2 cytokine dynamics in retina neural damage and protection reflect the complexity of immune responses during glaucoma pathogenesis. Cytokines under different circumstances, or actions on different effectors such as RGC, astrocytes, microglial cells, and Müller glial cells, may result in distinct consequences. Although accumulated evidence has already sketched an outline of the roles of cytokines in glaucoma, further detailed studies will facilitate an understanding of the ways in which they influence the pathogenesis of glaucoma.

Open Access This article is distributed under the terms of the Creative Commons Attribution Noncommercial License which permits any noncommercial use, distribution, and reproduction in any medium, provided the original author(s) and source are credited.

\section{References}

1. Marcic TS, Belyea DA, Katz B. Neuroprotection in glaucoma: a model for neuroprotection in optic neuropathies. Curr Opin Ophthalmol. 2003;14:353-6.

2. Wax MB, Tezel G. Neurobiology of glaucomatous optic neuropathy: diverse cellular events in neurodegeneration and neuroprotection. Mol Neurobiol. 2002;26:45-55.

3. Zhu J, Paul WE. CD4 T cells: fates, functions, and faults. Blood. 2008;112:1557-69.

4. Schroeter M, Jander S. T-cell cytokines in injury-induced neural damage and repair. Neuromolecular Med. 2005;7:183-95.
5. Alexander JJ, Anderson AJ, Barnum SR, Stevens B, Tenner AJ. The complement cascade: Yin-Yang in neuroinflammation-neuro-protection and -degeneration. J Neurochem. 2008; 107:1169-87.

6. Whitney NP, Eidem TM, Peng H, Huang Y, Zheng JC. Inflammation mediates varying effects in neurogenesis: relevance to the pathogenesis of brain injury and neurodegenerative disorders. J Neurochem. 2009;108:1343-59.

7. Hohlfeld R. Immunologic factors in primary progressive multiple sclerosis. Mult Scler. 2004;10(Suppl 1):S16-21. discussion S21-12.

8. Amantea D, Nappi G, Bernardi G, Bagetta G, Corasaniti MT. Post-ischemic brain damage: pathophysiology and role of inflammatory mediators. FEBS J. 2009;276:13-26.

9. Giunta B, Fernandez F, Nikolic WV, Obregon D, Rrapo E, Town $\mathrm{T}$, et al. Inflammaging as a prodrome to Alzheimer's disease. $\mathrm{J}$ Neuroinflammation. 2008;5:51.

10. Hendrix $S$, Nitsch R. The role of $T$ helper cells in neuroprotection and regeneration. J Neuroimmunol. 2007;184:100-12.

11. Tura A, Schuettauf F, Monnier PP, Bartz-Schmidt KU, HenkeFahle S. Efficacy of Rho-kinase inhibition in promoting cell survival and reducing reactive gliosis in the rodent retina. Invest Ophthalmol Vis Sci. 2009;50:452-61.

12. Abcouwer SF, Shanmugam S, Gomez PF, Shushanov S, Barber AJ, Lanoue KF, et al. Effect of IL-1beta on survival and energy metabolism of R28 and RGC-5 retinal neurons. Invest Ophthalmol Vis Sci. 2008;49:5581-92.

13. Amadi-Obi A, Yu CR, Liu X, Mahdi RM, Clarke GL, Nussenblatt $\mathrm{RB}$, et al. TH17 cells contribute to uveitis and scleritis and are expanded by IL-2 and inhibited by IL-27/STAT1. Nat Med. 2007;13:711-8.

14. Tezel G, Wax MB. Increased production of tumor necrosis factoralpha by glial cells exposed to simulated ischemia or elevated hydrostatic pressure induces apoptosis in cocultured retinal ganglion cells. J Neurosci. 2000;20:8693-700.

15. Yuan L, Neufeld AH. Tumor necrosis factor-alpha: a potentially neurodestructive cytokine produced by glia in the human glaucomatous optic nerve head. Glia. 2000;32:42-50.

16. Kitaoka Y, Kwong JM, Ross-Cisneros FN, Wang J, Tsai RK, Sadun AA, et al. TNF-alpha-induced optic nerve degeneration and nuclear factor-kappaB p65. Invest Ophthalmol Vis Sci. 2006;47:1448-57.

17. Nakazawa T, Nakazawa C, Matsubara A, Noda K, Hisatomi T, She $\mathrm{H}$, et al. Tumor necrosis factor-alpha mediates oligodendrocyte death and delayed retinal ganglion cell loss in a mouse model of glaucoma. J Neurosci. 2006;26:12633-41.

18. Hong S, Park K, Kim CY, Seong GJ. Agmatine inhibits hypoxiainduced TNF-alpha release from cultured retinal ganglion cells. Biocell. 2008;32:201-5.

19. Fisher J, Mizrahi T, Schori H, Yoles E, Levkovitch-Verbin H, Haggiag S, et al. Increased post-traumatic survival of neurons in IL-6-knockout mice on a background of EAE susceptibility. J Neuroimmunol. 2001;119:1-9.

20. Tezel G, Yang X, Yang J, Wax MB. Role of tumor necrosis factor receptor-1 in the death of retinal ganglion cells following optic nerve crush injury in mice. Brain Res. 2004;996:202-12.

21. Hirano T, Matsuda T, Nakajima K. Signal transduction through gp130 that is shared among the receptors for the interleukin 6 related cytokine subfamily. Stem Cells. 1994;12:262-77.

22. Akira S. IL-6-regulated transcription factors. Int J Biochem Cell Biol. 1997;29:1401-18.

23. Bonni A, Sun Y, Nadal-Vicens M, Bhatt A, Frank DA, Rozovsky I, et al. Regulation of gliogenesis in the central nervous system by the JAK-STAT signaling pathway. Science. 1997;278:477-83. 
24. Yen D, Cheung J, Scheerens H, Poulet F, McClanahan T, McKenzie B, et al. IL-23 is essential for T cell-mediated colitis and promotes inflammation via IL-17 and IL-6. J Clin Invest. 2006;116:1310-6.

25. Namekata K, Harada C, Kohyama K, Matsumoto Y, Harada T. Interleukin-1 stimulates glutamate uptake in glial cells by accelerating membrane trafficking of $\mathrm{Na}+\mathrm{K}+$-ATPase via actin depolymerization. Mol Cell Biol. 2008;28:3273-80.

26. Diem R, Meyer R, Weishaupt JH, Bahr M. Reduction of potassium currents and phosphatidylinositol 3-kinase-dependent AKT phosphorylation by tumor necrosis factor-(alpha) rescues axotomized retinal ganglion cells from retrograde cell death in vivo. J Neurosci. 2001;21:2058-66.

27. Koeberle PD, Gauldie J, Ball AK. Effects of adenoviral-mediated gene transfer of interleukin-10, interleukin-4, and transforming growth factor-beta on the survival of axotomized retinal ganglion cells. Neuroscience. 2004;125:903-20.

28. Sanchez RN, Chan CK, Garg S, Kwong JM, Wong MJ, Sadun AA, et al. Interleukin-6 in retinal ischemia reperfusion injury in rats. Invest Ophthalmol Vis Sci. 2003;44:4006-11.

29. Boyd ZS, Kriatchko A, Yang J, Agarwal N, Wax MB, Patil RV. Interleukin-10 receptor signaling through STAT-3 regulates the apoptosis of retinal ganglion cells in response to stress. Invest Ophthalmol Vis Sci. 2003;44:5206-11.

30. Zhang C, Li H, Liu MG, Kawasaki A, Fu XY, et al. STAT3 activation protects retinal ganglion cell layer neurons in response to stress. Exp Eye Res. 2008;86:991-7.

31. Nakazawa T, Takahashi H, Nishijima K, Shimura M, Fuse N, Tamai $\mathrm{M}$, et al. Pitavastatin prevents NMDA-induced retinal ganglion cell death by suppressing leukocyte recruitment. J Neurochem. 2007;100:1018-31.

32. Yoles E, Hauben E, Palgi O, Agranov E, Gothilf A, Cohen A, et al. Protective autoimmunity is a physiological response to CNS trauma. J Neurosci. 2001;21:3740-8.

33. Kipnis J, Avidan H, Markovich Y, Mizrahi T, Hauben E, Prigozhina $\mathrm{TB}$, et al. Low-dose gamma-irradiation promotes survival of injured neurons in the central nervous system via homeostasisdriven proliferation of T cells. Eur J NeuroSci. 2004;19:1191-8.

34. Latina MA, Belmonte SJ, Park C, Crean E. Gamma-interferon effects on human fibroblasts from Tenon's capsule. Invest Ophthalmol Vis Sci. 1991;32:2806-15.

35. Gillies M, Su T, Sarossy M, Hollows F. Interferon-alpha $2 b$ inhibits proliferation of human Tenon's capsule fibroblasts. Graefes Arch Clin Exp Ophthalmol. 1993;231:118-21.

36. Nguyen KD, Hoang AT, Lee DA. Transcriptional control of human Tenon's capsule fibroblast collagen synthesis in vitro by gamma-interferon. Invest Ophthalmol Vis Sci. 1994;35:3064-70.

37. Kelley MJ, Rose AY, Song K, Chen Y, Bradley JM, Rookhuizen $\mathrm{D}$, et al. Synergism of TNF and IL-1 in the induction of matrix metalloproteinase-3 in trabecular meshwork. Invest Ophthalmol Vis Sci. 2007;48:2634-43.

38. Yang J, Patil RV, Yu H, Gordon M, Wax MB. T cell subsets and sIL-2R/IL-2 levels in patients with glaucoma. Am J Ophthalmol. 2001;131:421-6.

39. Yang Z, Quigley HA, Pease ME, Yang Y, Qian J, Valenta D, et al. Changes in gene expression in experimental glaucoma and optic nerve transection: the equilibrium between protective and detrimental mechanisms. Invest Ophthalmol Vis Sci. 2007;48:5539-48. 